\section{PROGRAMAS DE SEGURIDAD DIRIGIDOS A BARRIOS EN LA EXPERIENCIA CHILENA RECIENTE ${ }^{1}$}

Hugo Frühling ${ }^{2}$ y Roberto Gallardo 3

\section{SECURITY PROGRAMS AIMED AT NEIGHBORHOODS, THE RECENT CHILEAN EXPERIENCE ${ }^{1}$}

Hugo Frühling ${ }^{2}$ y Roberto Gallardo ${ }^{3}$

\section{Abstract}

Crime analysis has demonstrated the difficulties certain communities have to fit within the values, social and economic system. These organizational problems are characterized by the concentration of social disadvantage and low organizational capacities when it comes to regulating the behavior of people. This situation has led to the creation of specific programs aimed at controlling crime in socially disorganized neighborhoods where structural socio cultural conditions have triggered high delinquency rates. This paper analyzes 
condiciones socio-culturales de carácter estructural. El propósito de este trabajo, a través del uso de información primaria y la revisión de antecedentes secundarios, es analizar políticas públicas implementadas en Chile durante años recientes, particularmente en la ciudad de Santiago, cuyos objetivos principales se han orientado a la reducción de los niveles de criminalidad y violencia presentes en determinados sectores de la ciudad mediante la intervención en barrios específicos en los cuales se espera reducir la criminalidad. Este trabajo centra su análisis en tres programas: Comuna Segura, Barrio Seguro y Barrios en Paz.

\section{PALABRAS CLAVE: VICTIMIZACIÓN, BARRIOS, PROGRAMAS DE SEGURIDAD, POLÍTICAS PÚBLICAS DE SEGURIDAD EN CHILE.}

Fecha de recepción: 15.11.11

Fecha de aceptación: 23.03.12

1 Este estudio se desarrolló en el marco del Proyecto Anillos en Ciencias Sociales SOC-09 “Crimen y Violencia Urbana. Aportes de la Teoría Ecológica del Delito al Diseño de Políticas Públicas", financiado por CONICYT. Los autores agradecen el apoyo en la investigación recibido de parte de Felipe Torres y Pablo Mansilla.

2 Chile. Director del Centro de Estudios en Seguridad Ciudadana del Instituto de Asuntos Públicos de la Universidad de Chile.

3 Chile. Fundación Paz Ciudadana. public policies intended to reduce criminality and violence through intervention in specific neighborhoods in Chile, especially in Santiago. This paper reviews three programs: Comuna Segura, Barrio Seguro and Barrios en Paz.

\section{KEYWORDS: VICTIMIZATION, NEIGHBORHOODS, SECURITY PROGRAMS, PUBLIC POLICIES ON SECURITY IN CHILE}

Received: 15.11.11

Accepted: 23.03.12

1 This paper is part of the ANILLOS Social Sciences Research Project SOC-09 "Crime and Urban Violence. Contributions of Ecology Theory to the Design of Public Policies" funded by CONICYT. The authors of this paper thank the contribution of Felipe Torres and Pablo Mansilla.

2 Chile. Director of the Centro de Estudios en Seguridad Ciudadana, Instituto de Asuntos Públicos, Universidad de Chile.

3 Chile. Fundación Paz Ciudadana. 


\section{Introducción}

Por más de un siglo se sabe que la distribución espacial de la violencia y el delito no es arbitraria y que tiende a concentrarse de manera relativamente estable en determinadas áreas urbanas. Una importante contribución al análisis de la relación entre lugares y crimen encuentra su origen en los trabajos de Shaw y $\mathrm{McKay}^{4}$, quienes argumentaron que existen relaciones significativas entre niveles delictuales y determinadas condiciones sociales prevalecientes en la comunidad. Esta línea de pensamiento ha dado origen a una significativa producción académica centrada en el análisis de procesos sociales que tienen lugar a nivel de vecindarios y que podrían ser explicativos de la variación espacial del delito en las ciudades. Sampson, Morenoff y Gannon-Rowley ${ }^{5}$ arribaron a la conclusión que una concentración de la pobreza, unida a bajos niveles de cohesión social en determinados barrios, son predictivos de desorganización social, conductas desviadas y de riesgo entre adolescentes. A su vez, estudios realizados por Sampson ${ }^{6}$ y por Block ${ }^{7}$, revelan una correlación negativa entre estabilidad residencial y niveles delictuales, presumiblemente, como producto del efecto negativo de

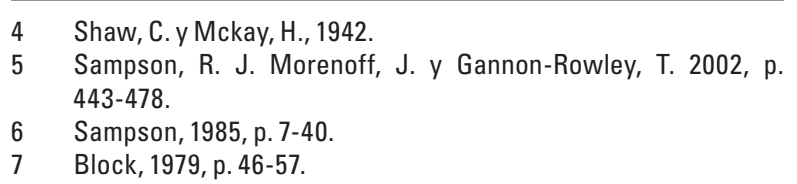

la inestabilidad residencial sobre el control social informal a nivel de barrios.

Más recientemente aún, diversos estudios empíricos han demostrado que áreas pequeñas, tales como cruces de calles determinados o grupos de viviendas económicas específicas podrían concentrar desproporcionados niveles de violencia para su tamaño. ${ }^{8}$ Desde la perspectiva de las políticas públicas, los estudios que se mencionan sugieren diversos cursos de acción posibles para reducir el delito: primero, focalizar recursos en áreas geográficas limitadas de intervención, ya que ellas atraen la producción de delitos, o crean condiciones favorables para que en ellas crezcan personas o grupos que pueden potencialmente infringir la ley. En segundo lugar, potenciar estrategias que combinen el control del sistema de justicia penal, con otras que mejoren las condiciones de vida existentes en barrios en los que existen condiciones de desventaja social, a efectos de aumentar el control social informal sobre conductas inconvenientes o ilegales.

La focalización de políticas de seguridad en áreas geográficas limitadas, que es una de las consecuencias de los estudios citados, ha guiado el accionar gubernamental de Chile desde el año 2000. Ese año, el gobierno inicia la ejecución de programas

\footnotetext{
8 Para un análisis de la evidencia más reciente, respecto de concentración de problemas delictuales en áreas pequeñas, ver Braga A. y Weisburd D., 2010, p. 1-6.
} 
destinados a reducir los niveles delictuales que se efectúan en el territorio local, y que intentan complementar el accionar del sistema de justicia penal con programas preventivos de diverso carácter ${ }^{9}$. Un primer esfuerzo en este sentido, lo constituyó el Programa Comuna Segura Compromiso 100, que se inicia en el año 2000 en doce comunas del país y que experimenta diversos cambios, hasta transformarse el año 2007 en el Programa Planes Comunales de Seguridad Pública.

De manera paralela al Programa Comuna Segura, se inicia una primera intervención focalizada en barrios a iniciativa del Ministerio del Interior el año 2001, que recibe el nombre de "Barrio Seguro"10. A diferencia de la anterior, se focaliza en áreas territoriales más pequeñas, caracterizadas por la predominancia de delitos contra las personas y narcotráfico en la vía pública. El Programa abarcó gradualmente tan solo 12 barrios $^{11}$.

El año 2010, el nuevo gobierno del Presidente Sebastián Piñera dio especial importancia a la reducción del delito, criticando la gestión de las administraciones que le habían precedido en el poder. Para ello dio a conocer una nueva política de seguridad expuesta en el Plan de Seguridad Pública 2010 - 2014 "Chile Seguro", en el que anuncia el término de los programas de seguridad focalizados en municipios y su remplazo por el llamado Programa Barrio en Paz, caracterizado por la focalización de los recursos policiales y preventivos del Estado en un importante número de barrios residenciales y comerciales.

Este artículo se centra en el análisis de los tres Programas mencionados, con énfasis en los siguientes aspectos fundamentales: los criterios usados para seleccionar los barrios que serían objeto de la intervención en cada caso; las líneas de intervención definidas para actuar en la prevención del delito en cada Programa y las evaluaciones conocidas de los resultados de cada uno de ellos. Para esto, se realizaron una serie de entrevistas a actores considerados claves, entre los que se encontraban dirigentes vecinales, coordinadores territoriales, funcionarios gubernamentales, entre otros, como así mismo se utilizó documentación pública y estudios académicos para complementar aquellas observaciones.

Del desarrollo de la investigación realizada se desprende que la elección de los barrios a ser intervenidos en cada caso ha respondido solo parcialmente a criterios objetivos fundados en evidencia. Más bien se ha debido a una multiplicidad de circunstancias, tales como las prioridades establecidas por los alcaldes en algunos casos, o la capacidad de algunos sectores para hacer pesar su opinión ante el gobierno.

9 Zúñiga, L. ,2010.

10 Manzano, L., 2009.

11 Martínez, F., 2007. 
Por otra parte, en las líneas de intervención policial implementadas destaca en el caso de Barrio Seguro y de Barrio en Paz un fuerte énfasis en la reducción del microtráfico, sin que exista la certeza de que ello contribuya a la reducción del delito en otras áreas de la ciudad. Ello obliga a repensar las tácticas policiales utilizadas.

Ha sido común que en estos programas se haya puesto énfasis en trabajar con las poblaciones afectadas por el delito, mediante enfoques comunitarios o colectivos dirigidos a incrementar el control social informal sobre las conductas de los integrantes de la comunidad. Nuestra investigación no parece demostrar que exista una relación directa y robusta entre control social informal y victimización. Ello no quiere decir que reforzar la disposición a participar colectivamente carezca de todo sentido, ya que esa disposición es muchas veces necesaria para que los programas de intervención funcionen, pero no existe claridad de que tenga un impacto directo sobre la victimización en el barrio.

Más allá de estos aspectos críticos, son múltiples los aprendizajes que se han venido incorporando de manera paulatina a la ejecución de programas de seguridad dirigidos a áreas urbanas que se caracterizan por la concentración de desventajas sociales, por la presencia de desorganización social, e inseguridad objetiva y subjetiva, los que se describirán en el artículo. Es a partir del balance entre aspectos críticos y avances realizados por los programas referidos, que se realizan recomendaciones de política pública destinados a mejorar esas intervenciones.

\section{Evidencia sobre la realidad delictual en barrios}

La liberalización del mercado del suelo que tuvo lugar durante los años ochenta, unida a los cambios estructurales que experimentaron las políticas sociales ahondaron al menos dos dimensiones de segregación residencial en las grandes ciudades del país. La primera, la conformación de áreas o barrios socialmente homogéneos habitados por sectores de bajos ingresos. La segunda, la aguda percepción de esos sectores de que padecían de segregación subjetiva ${ }^{12}$. Mientras la presencia de los sectores de más altos ingresos en la ciudad se dispersaba, la de los pobres tendía a concentrarse en la periferia, producto del encarecimiento del precio del suelo en el resto de la ciudad ${ }^{13}$.

Este fenómeno habría atraído, asimismo, la concentración espacial de serios problemas sociales, tales como deserción escolar, desapego por el sistema legal, concentración en esos espacios de puntos

12 Sabatini, F., Cáceres, G. y Cerda, 2001, p. 21-42.

13 Cáceres, G. y Sabatini, F., 2004. 
de venta pública de drogas ilícitas y de violencia organizada. Los estudios a nivel municipal y barrial parecen confirmar que en los sectores de bajos ingresos se concentran manifestaciones de la violencia diferentes de las que ocurren en otros sectores de la ciudad.

El año 2002 los investigadores Araya y Sierra diseñaron un Índice de Vulnerabilidad Social y Delictual que utilizó el Ministerio del Interior para determinar los municipios que recibirían fondos del Programa Comuna Segura Compromiso $100^{14}$. El estudio se profundizó el año 2009, diseñando un índice de vulnerabilidad socio-delictual, que identificaba factores de riesgo sociales que tenían incidencia respecto de la tasa de condenados por delitos residentes en la comuna ${ }^{15}$. Dicho estudio demostraba que las comunas de mayor vulnerabilidad social de Santiago tienden a concentrar un número más alto de condenados por la comisión de delitos y que los delitos contra las personas se acumulan en su entorno. Por el contrario, los delitos contra la propiedad como el robo en lugar deshabitado o habitado, entre otros, que son más numerosos, se producen en lugares donde existen oportunidades para cometerlos, por tratarse de

14 El modelo considera variables demográficas y sociales y define como variable dependiente la tasa de personas recluidas que declaran residir en la comuna y que se encuentran acusadas de cometer delitos de la categoría "delincuencia común" pero también el homicidio y las lesiones. Ver: Araya, J. y Sierra D., 2002.

15 Araya, J., 2009. áreas donde se acumulan servicios o comercio y en las comunas donde existe mayor disponibilidad de bienes de consumo durables ${ }^{16}$.

Un estudio posterior realizado por Emiliano Oteíza Diamante sugiere a ese respecto, que el lugar de origen de la delincuencia, entendido como los municipios donde residen las personas detenidas por Carabineros por la comisión de robos con violencia o intimidación y robos en lugar habitado, tiende a concentrarse mucho más que los lugares donde se producen estos delitos, de lo que deduce la necesidad de concentrar en esa áreas de origen programas de prevención social. Para ello, asevera que es de gran importancia profundizar en la focalización de la información que permita identificar en cada comuna las áreas críticas proveedoras y atractoras de delincuentes ${ }^{17}$.

Información complementaria proviene de una encuesta realizada el año 2010, específicamente para el estudio "Crimen y Violencia Urbana. Aportes de la Teoría Ecológica del Delito al Diseño de Políticas Públicas", que buscó determinar las variables que permiten explicar la presencia de niveles elevados de victimización y temor al delito en algunos barrios del Gran Santiago (GS) en comparación con otros.

16 Frey, A. 2009; Frühling, H. y Sandoval, L., 1995, p. 137-159.

17 Oteiza, E., 2011, p. 9-22. 
Los principales resultados de aquel trabajo permiten sugerir que en barrios del Gran Santiago que presentan elevados niveles de percepción de violencia en el entorno, percepción de que se cometen ilícitos de drogas, percepción de desórdenes sociales, percepción de bajo apego a la legalidad y que son de bajos ingresos, es más probable constatar altos niveles de inseguridad y, en menor medida, de victimización en el propio territorio respecto a barrios donde se configuren escenarios diferentes al descrito ${ }^{18}$. Al parecer esos barrios que corresponden al perfil de barrios vulnerables atraen la comisión de ilícitos de drogas, de riñas y desorden social en el espacio público, pero no así la comisión de los delitos más numerosos que detectan las encuestas de victimización, como los hurtos y robos. Por otra parte, el control social informal medido a través de la pregunta "¿Cuán probable es que sus vecinos intervengan en determinadas situaciones infractoras de la ley o de la convivencia en el barrio?", no parece incidir en los niveles de victimización.

La evidencia presentada indica la necesidad de focalizar adecuadamente recursos y programas en áreas especialmente críticas, para lo cual es crucial contar con información adecuada. Los barrios que acumulan desventajas sociales requieren de

18 En el anexo A se describe la metodología y análisis de la encues ta, mientras que el Anexo B da cuenta de la operacionalización de las variables consideradas en este análisis. programas preventivos dirigidos a impedir el desarrollo de carreras delictuales. Por otra parte, en el ámbito del control policial, esos barrios requieren enfrentar diversas manifestaciones de desorden social, venta de drogas y riñas, lo que requerirá de tácticas policiales distintas de las que se despliegan para prevenir la comisión de robos y hurtos. La evidencia no parece apoyar la realización de programas dirigidos a incrementar el control social informal en el barrio como medio para disminuir el delito.

De esta forma, y frente a la concentración espacial de desventajas sociales constitutivas de factores de riesgo de carácter criminógeno, distintos gobiernos hasta el día de hoy, han desarrollado diversos programas sociales que se ejecutaron en el espacio comunal o de barrios, y cuyos objetivos han sido los de mejorar la calidad de vida de los habitantes de las zonas a intervenir en cualquiera de sus dimensiones.

Algunos de estos programas implicaron inversiones dirigidas a la construcción o reparación de infraestructura urbana y equipamiento comunitario de barrios con deterioro urbano; otros tenían por objetivo la entrega de herramientas sociales, formativas y laborales que fortalecieran a los beneficiarios, otros, a su vez, se dirigían a crear actividades 
de desarrollo cultural, mientras que otros, por fin, se proponían ser un aporte directo a la reducción del delito y de la percepción de inseguridad en las comunidades. Es a estos últimos programas que se dirige el análisis que sigue.

\section{Programas de Seguridad a nivel local llevados a cabo entre los años 2000 y 2010}

\section{PROGRAMA COMUNA SEGURA COMPROMISO 100}

\section{Objetivos y Criterios de Selección de Áreas INTERVENIDAS}

El año 2000 se diseña desde el Ministerio del Interior junto a la Asociación Chilena de Municipalidades y la Fundación Paz Ciudadana, el "Plan Comuna Segura Compromiso 100" cuyo énfasis se orientó a constituir una estrategia preventiva en el ámbito de la seguridad ciudadana en el país focalizada en municipios. El programa se propuso crear un modelo de prevención de la delincuencia que pudiese generar acciones que perdurasen en el tiempo en las comunidades que recibieran los fondos del nivel central, en función de dos conceptos centrales: fortalecer el enfoque preventivo del delito y el aumento de capital social ${ }^{19}$.

19 Ministerio del Interior de Chile, 2001.
Entre los objetivos específicos del programa estaban: fortalecer la participación comunitaria y la coordinación intersectorial en la prevención y control de la delincuencia mediante la aplicación de soluciones locales. Para el cumplimiento de sus propuestas, el Programa se implementó basándose en tres componentes fundamentales: el Consejo Comunal de Seguridad Ciudadana, la Secretaría Técnica Comunal y la Mesa Técnica Comunal. Los componentes administrativos tenían una relación con el gobierno central y con el municipio ${ }^{20}$.

Comenzó a nivel nacional como un piloto en 12 comunas de más de 70 mil habitantes seleccionadas por la División de Seguridad Ciudadana del Ministerio del Interior que fueron ingresando según criterios de prioridad. Para la selección de comunas iniciales en 2000 y 2001, se utilizó la siguiente ponderación de factores: tasa de denuncias por robo con violencia (20\%); tasa de denuncias por robo con fuerza (15\%); violencia intrafamiliar (20\%); prevalencia del consumo de drogas (10\%); índice de pobreza (35\%). Esos criterios eran correctos desde la perspectiva de entregar apoyo financiero a comunas con un elevado nivel de pobreza, merecedoras por tanto de apoyo de parte del gobierno central, pero los indicadores de presencia de delitos no eran adecuados para seleccionar comunas en las que se llevarían a cabo programas de prevención social del delito, dado que los autores

20 Lunecke, A. y Guajardo García, C., 2009, p.3. 
de esos hechos podían tener residencia en otras comunas $^{21}$

A partir de 2003, la selección de las comunas que se fueron agregando al Programa utiliza la siguiente ponderación de factores: Îndice de Vulnerabilidad Social Delictual (50\%) ; número total de población comunal (30\%), análisis de delitos cometidos en la comuna, mediante el estudio de las denuncias asociadas a delitos de mayor connotación social en los últimos tres años (20\%).

El Índice de vulnerabilidad social fue el producto de una investigación aplicada en las 63 comunas chilenas que superaban los 70.000 habitantes. El objetivo del estudio era investigar la eventual asociación entre diversas condiciones sociales de riesgo y el origen de conductas delincuenciales.

Para ello se definió un conjunto de dimensiones (pobreza, educación, empleo, drogas, (clima familiar y entorno) que de acuerdo con la literatura podían considerarse asociadas a conductas infractoras de la ley penal. Estas dimensiones se midieron a través de indicadores que se correlacionaron con la variable dependiente población penal condenada con origen en la comuna ${ }^{22}$. Finalmente, se obtuvo un índice que permitía comparar las comunas entre sí y establecer aquellas donde la intervención era prioritaria.

21 Más Comunidad más Prevención, No 1, pp. 8- 16, 2004

22 Araya J.y Sierra D. 2002.
Los criterios de selección, perfectibles, otorgaban un peso significativo a factores de riesgo sociales, y su correlación con condenados provenientes de esas comunas, lo que podía incidir en la determinación de las comunas que requerían de programas preventivos. La selección de comunas con una concentración elevada de población permitía evitar, a su vez, que el programa se focalizara en comunas rurales con alta concentración de factores de riesgo social, pero que tenían escasa asociación con conductas delictuales. Por otra parte, se consideraban las denuncias por determinados delitos presentes en el espacio público, a fin de seleccionar comunas que pudieran requerir de intervenciones de prevención situacional.

Inicialmente, no existía una determinación de las áreas más críticas de cada comuna basada en indicadores objetivos. Posteriormente, el Ministerio del Interior entregó a los municipios mapas que indicaban la distribución de los delitos de mayor connotación social en el espacio comunal, pero no así información respecto del domicilio de origen de las personas condenadas y residentes en el municipio. En algunos casos los programas efectivamente se dirigían hacia las áreas más críticas en materia de seguridad del municipio respectivo, mientras que en otros podían no hacerlo. 


\section{Cobertura, Líneas de intervención y asignación de FONDOS}

Hasta su remplazo por el Programa Plan Comunal de Seguridad en 2006, Comuna Segura alcanzó una cobertura de 82 comunas sobre un total de 346 en el país. El Programa financió y capacitó a secretarios técnicos de seguridad en cada comuna, promovió la constitución de los Consejos Comunales de Seguridad Ciudadana y la instalación de mesas técnicas de seguridad donde participaban funcionarios que discutían los aspectos técnicos involucrados en las intervenciones respectivas.

Durante su primera etapa, las asignaciones correspondientes a los diversos municipios se realizaron a través de Fondos Concursables que financiaron iniciativas de prevención en el ámbito de la seguridad local. La evaluación interna del propio Ministerio fue que las organizaciones que postulaban a dichos Fondos carecían muchas veces de la capacidad técnica y administrativa para ejecutar los proyectos respectivos, que las temáticas abordadas eran demasiado diversas y que los montos eran demasiado pequeños, todo lo cual redundaba en un limitado impacto sobre los indicadores de seguridad comunales ${ }^{23}$. Tampoco se garantizaba que esos proyectos incidieran en vecindarios o comunidades que experimentaban situaciones de inseguridad importantes.

23 Zúñiga L., 2010, p. 12.
Para responder en parte a esos problemas, se reformuló el Programa en 2006, acotando las áreas programáticas susceptibles de ser financiadas en función de las establecidas en la Estrategia Nacional de Seguridad Pública y remplazando los Fondos Concursables por los Fondos de Apoyo a la Gestión Municipal, transferencias directas realizadas a los municipios para que éstos los ejecutaran de acuerdo a las prioridades establecidas en un Plan Comunal de Seguridad.

Las áreas temáticas eran:

a) Prevención

- Abordaje de la violencia en establecimientos escolares

- Prevención con niños y adolescentes vulnerables

- Prevención de la violencia en el ámbito comunitario

- Prevención a través del diseño urbano

b) Rehabilitación

- Para hombres agresores en ámbito familiar

- Reinserción social post-penitenciaria

c) Asistencia a víctimas

Las evaluaciones del Programa Comuna Segura y sus modificaciones, destacan positivamente que se involucrara al municipio y a la comunidad en la lucha contra el delito dado que, de forma previa a 
la existencia de este programa, se pensaba que esa tarea sólo correspondía a la policía y al gobierno central ${ }^{24}$. Sin embargo, también se sostiene que en el plano administrativo se evidenciaba demora en la entrega de los recursos, falta de continuidad asegurada de estos, escasa diferencia entre los montos asignados a comunas de muy diferentes dimensiones y población.

A su vez, existen dos evaluaciones analíticas del Plan Comuna Segura. Un estudio publicado por el Banco Interamericano de Desarrollo, mediante un examen estadístico, determinó que en aquellas comunas que formaron parte del Programa los indicadores de delitos, contra las personas y la propiedad, hubiesen sido un 19\% más altos de no haber existido Comuna Segura ${ }^{25}$.

Sin embargo, desde otra perspectiva, un análisis econométrico concluye que Comuna Segura no logró elevar los costos, ni alternativamente, reducir los beneficios esperados de delinquir, por tanto se presume que no consiguió una mejora en las oportunidades económicas en los barrios intervenidos o garantizar que grupos vulnerables hayan conseguido una mayor integración ${ }^{26}$.

24 Lunecke, A. y Guajardo García, C., 2009.

25 Ruprah, I., 2008.

26 Beyer, H. y Vergara, R., 2006.

\section{PROGRAMA BARRIO SEGURO}

\section{Orígenes}

Este Programa se desarrolla a partir de intervenciones del Ministerio del Interior en algunas poblaciones denominadas emblemáticas, iniciadas el año 2001, gatilladas por la difusión por los medios de comunicación de la presencia pública y notoria de bandas de narcotraficantes en estos sectores ${ }^{27}$. Según expresan funcionarios de la División de Seguridad Pública del Ministerio del Interior de esa época, esas intervenciones constituyen también una reacción gubernamental frente a la expresión de descontento de vecinos de estos barrios, que exigen la necesidad de aplicar la ley frente al tráfico de drogas y otros delitos recurrentes como el porte de armas en el espacio público, riñas y tiroteos ${ }^{28}$.

Las intervenciones se realizan fuera del marco del Programa Comuna Segura, dado que éste se llevaba a cabo en territorios demasiado amplios para los requerimientos de acciones que debían focalizarse en barrios críticos, y debido a la necesidad de abordar una estrategia de intervención policial que

27 Emol. Gobierno se querelló contra "reina de la pasta base". [En línea] Septiembre de 2001. [Fecha de consulta: 07 de junio de 2011] Disponible en: http://www.emol.com/noticias/nacional/ detalle/detallenoticias. asp?idnoticia $=66921$.

28 Entrevistas realizadas en Julio de 2011. 
quedaba fuera de Comuna Segura por su carácter preventivo $^{29}$.

De esta forma, lo que comenzó como una intervención en determinados barrios, fue progresivamente ampliándose a otras poblaciones y adquiriendo contornos programáticos más definidos. La primera etapa, desde 2001 a 2003, puede definirse como de "pilotaje". Ella incluyó la intervención en cuatro poblaciones del área metropolitana: en 2001 La Legua Emergencia (San Joaquín), en 2002 las poblaciones La Victoria (Pedro Aguirre Cerda) y Santa Adriana (Lo Espejo), y en 2003 la población Lo Amor-Intendente Saavedra (Cerro Navia). Durante esa primera etapa, la intervención del programa Barrio Seguro (BS) se caracterizó por ser una estrategia de carácter reactivo frente a la problemática de violencia organizada que enfrentaban estos barrios.

\section{Objetivos y metodología de Selección de los barrios}

El Programa fue adquiriendo objetivos generales y específicos con el tiempo. Estos, a su vez, no se encontraban ligados a un Plan Nacional de Seguridad Pública, a cuya meta de disminución de la victimización nacional se propusiera aportar. El principal objetivo del Programa Barrio Seguro puede definirse como contribuir a la disminución de la violencia y el temor en barrios (12 en total)

29 Martínez, F., 2007, p. 1.

160 revista invi № 74 / Mayo 2012 / Volumen № 27: 149-185 caracterizados por la acción y control de grupos de narcotraficantes cuya actuación vulneraba la seguridad y convivencia en esas comunidades ${ }^{30}$.

A su vez, sus objetivos específicos eran los siguientes:

- Impulsar desde el nivel central la ejecución de acciones de control del narcotráfico, crimen organizado y violencia delictiva, a través de la acción policial.

- Rescatar los espacios públicos y asegurar las condiciones de seguridad que permitieran su utilización por parte de los ciudadanos.

- Fomentar la participación de vecinos y organizaciones locales en la planificación y en el desarrollo de acciones preventivas de la violencia ${ }^{31}$.

La selección de los barrios intervenidos no ocurrió en un proceso público de acuerdo con indicadores conocidos previamente. Sin embargo, parecen haberse utilizado indicadores de denuncias ante la policía por delitos contra las personas como homicidios y violaciones, e información policial referente a la existencia de puntos de venta de drogas o presencia de organizaciones dedicadas al tráfico de drogas. Otros entrevistados indican que un factor que podría haber impulsado la selección de algunos de estos barrios podría haber sido la

30 Lunecke, A., 2006, p. 3.

31 Martínez, F., 2007, Pág. 4.

ARTÍCULO: Programas de seguridad dirigidos a barrios en la experiencia chilena reciente

Hugo Frühling y Roberto Gallardo 
visibilidad y presencia en los medios de los lugares intervenidos, que precisamente los convertía en emblemáticos ${ }^{32}$.

Así mismo, un rol central en la selección de barrios y en los componentes del Programa parece haber sido un diagnóstico sociológico respecto de las características de los barrios llamados vulnerables. Esa caracterización fue aportada por investigadores de la Universidad Alberto Hurtado en las poblaciones Santa Adriana y José María Caro. De ese diagnóstico se desprende que los barrios críticos suelen ser espacios que comparten una historia común, ya que fueron ocupados y lo siguen siendo, por personas y grupos de bajos ingresos, por lo que nunca han reunido las condiciones de infraestructura deseables ${ }^{33}$.

Sin embargo, entrevistas realizadas a dirigentes sociales de algunos barrios que fueron parte de Barrio Seguro, indicarían que la elección de los barrios, si bien muchas veces responde a criterios de focalización provenientes de datos oficiales, a la voz de los entrevistados no parecerían reflejar adecuadamente realidades específicas de cada territorio. Esto es, reconociéndose la existencia de algunas falencias en términos de seguridad en ciertos

32 Con "presencia en los medios" hacemos a alusión a la frecuencia con que aparecen en los medios de comunicación masivos determinados conjuntos poblacionales que son sindicados como foco de delincuencia. Entrevista a Azún Candina, julio 2011.

Lunecke A. y Ruiz J. C., 2007. barrios, no siempre los habitantes coinciden con los métodos de selección o con las actividades que conllevaron las intervenciones.

El principal problema que declaran los habitantes de esos barrios en las investigaciones cualitativas se relaciona con el tráfico de drogas que causa altos niveles de temor en la población, ya que lleva al uso de la violencia en el espacio público, con sus consecuencias de porte de armas y disputas interpersonales ${ }^{34}$. A la oferta de drogas se agrega como contraparte la prevalencia elevada de consumo de alcohol y de pasta base entre jóvenes, que inciden en el desorden y falta de cuidado del espacio público ${ }^{35}$.

\section{Líneas de Intervención del Programa Barkio Seguro}

En una primera etapa, las intervenciones realizadas son bastante flexibles, combinando acciones policiales, con otras movilizadoras y de ocupación del espacio público. Sin embargo, a fines de 2003 el equipo del programa analizó los efectos del trabajo realizado, arribando a la conclusión de no haber logrado terminar con la violencia armada y que las intervenciones realizadas carecían de foco y de sustentabilidad. Las dificultades para focalizar se hacían presentes, en parte porque los residentes en

34 Eissmann, I. y Lunecke, A., 2004.

35 Lunecke, A. y Ruiz, J.C., 2007. 
las poblaciones intervenidas eran muy numerosos, ya que no existía una definición previa respecto de lo que se entendería por población o barrio. Un ejemplo de ello es la intervención en la Población José María Caro, que se concentró en dos sectores cuya población era de 18.000 personas ${ }^{36}$.

Con presencia variable en cada uno de los barrios intervenidos, existió en todos un incremento importante de la presencia policial, aumento de los controles de identidad y patrullaje de los puntos de venta de drogas. Asimismo, se realizaron acciones dirigidas a investigar y apresar a los cabecillas de las redes de narcotráfico. Estas acciones tuvieron éxito, pero no se sustentaron en el tiempo, como lo ilustra el ejemplo de La Legua Emergencia que continúa siendo un vecindario de extrema peligrosidad, donde se acopia y distribuye droga, a pesar de las recurrentes intervenciones policiales ${ }^{37}$.

Las otras líneas de acción que se estandarizaron fueron, primero, la de movilización comunitaria, que inicialmente buscaba desarrollar el liderazgo e iniciativa de los líderes del sector intervenido, pero que progresivamente, en la medida en que se van agregando nuevos barrios, realiza proyectos dirigidos a: i) el fortalecimiento comunitario y las acciones orientadas al fomento de la participación, la asociatividad, y el desarrollo de una identidad fuerte en el barrio; ii) infraestructura comunitaria:

36 Martínez, F., 2007.

37 Villarrubia, G., 2012.

162 revista invi № 74 / Mayo 2012 / Volumen № 27: 149-185 consistente en proyectos destinados a mejorar, recuperar espacios públicos y de recreación, y iii) apoyo a las condiciones económicas de los vecinos, favoreciendo su capacidad de emprender ${ }^{38}$. Tal como indicamos previamente, de la encuesta realizada en barrios de Santiago durante 2010 no parece desprenderse que un incremento del control social informal tenga impacto sobre el delito cometido en el barrio.

Una segunda línea de trabajo se centró en la prevención dirigida a grupos de riesgo (niños y jóvenes). La tercera se centró en un trabajo inicial focalizado en la reinserción social de personas en conflicto con la ley. Se buscaba crear planes personalizados que ofrecieran alternativas de desarrollo personal y familiar para adultos que habían cometido delitos. La cuarta y última se denominó Acceso a la Justicia. En lo principal se dirigió a intentar reducir los niveles de impunidad existentes en esos barrios intervenidos por el Programa, mediante la presentación de querellas en contra de imputados por cometer delitos con violencia o asociados al narcotráfico.

A fin de ejecutar los programas el Ministerio del Interior contrató coordinadores barriales encargados de la supervisión de las intervenciones realizadas en barrios por parte de organizaciones no gubernamentales, consultoras privadas y universidades. Existe alguna evidencia que indica que éstos se vieron

38 Turró Ortega, C., Ramírez Corvera, M.T., Krause Jacob, M., 2007, p. 375-392. 
superados por la cantidad de iniciativas y de actores involucrados en los proyectos que confluyeron en los barrios incluidos en el Programa ${ }^{39}$. La inexistencia de una evaluación de todo el Programa de Barrio Seguro impide determinar la medida en que esto efectivamente ocurrió de manera generalizada ${ }^{40}$. El año 2006 el Programa Barrio Seguro fue aunado con el Plan Comunal de Seguridad dando término a su existencia como programa independiente. En parte, la decisión obedeció a la necesidad de entregar mayor participación a los municipios, desplazados de las intervenciones realizadas, las que se concentraron en el Ministerio del Interior. Por otra parte, es probable que las nuevas autoridades del Ministerio del Interior, que asumieron en 2006 bajo la Presidenta Michelle Bachelet, desconfiaran respecto de la posibilidad de que el Programa tuviera éxito en barrios cuyas condiciones sociales y delincuenciales eran particularmente resistentes a los programas gubernamentales.

39 Entrevista a Gloria Rodríguez - dirigente vecinal de la población La Victoria, actual concejal por la comuna de Pedro Aguirre Cerda-, quien deja entrever que una de las razones por las cuales las intervenciones programáticas en la población La Victoria no surtieron efecto, fue por la inexistencia de una intervención orgánica, sistematizada, que no "saturase" a los pobladores del lugar. Esto habría impedido a los habitantes del lugar adquirir la percepción de un abordaje armónico y bien planificado de las iniciativas ejecutadas en su territorio, por parte del Estado y las demás instituciones -consultoras, universidades, ONG. 40 Se conocen sólo estudios de caso y no de conjunto de la expe-
riencia, pero no se trata de estudios de impacto. Ver por ejemplo, Asesorías para el Desarrollo, 2003.

\section{La intervención en Barrios en el contexto de la Política de Seguridad del gobierno de Sebastián Piñera: el Programa Barrio en Paz}

\section{BARRIO EN PAZ COMERCIAL: OBJETIVOS DEL PROGRAMA Y SELECCIÓN DE LOS BARRIOS A INTERVENIR}

El gobierno de Sebastián Piñera otorga gran prioridad a la reducción del delito y muchas de sus propuestas iniciales tienen un énfasis en el control de imputados por la comisión de delitos y de personas que gozaban de libertad y debían cumplir con medidas cautelares ${ }^{41}$. En agosto de 2010 se dio a conocer el Plan Chile Seguro, para el periodo 2010 2014, el que tiene dos metas muy concretas: reducir

41 Frühling H., 2011, p. 113-126. 
el porcentaje de hogares victimizados en un $25 \%$ y reducir en un 25\% los delitos ocurridos en el espacio público, esto es, robos por sorpresa, robos con violencia e intimidación, robos de vehículos y de objetos de vehículos ${ }^{42}$. Para obtener esos resultados el nuevo gobierno considera que el barrio es la "unidad básica de intervención" lo cual implica poner término a los programas de carácter municipal que se habían ejecutado hasta ese momento.

Dicho Plan indica que la nueva focalización en barrios obedece a la constatación de que Programas anteriores no habían demostrado efectividad en la reducción del delito.

"Las evaluaciones realizadas al Fondo de Apoyo a la Gestión Municipal (FAGM) han señalado que "no existe impacto en la reducción del delito o que es mínimo" o que no ha tenido la eficacia esperada. La falta de evaluaciones de resultados y la constatación de múltiples problemas en el modelo de administración del FAGM, ha hecho imperioso el diseño de una nueva estrategia de colaboración entre el Gobierno Central y el nivel local; esta nueva mirada en la gestión de los programas ha determinado que la focalización ya no se realizará a nivel comunal, sino barrial"43.

Esta aseveración es poco precisa. Primero, porque como indicamos, las evaluaciones no eran concluyentes, aunque fueron numerosas, pero poco

42 Ministerio del Interior y Seguridad Pública, 2010, p. 20.

43 Unidad de Prevención Dirección de Seguridad Pública Ministerio del Interior, Santiago, Chile, 2011, p. 5. conocidas $^{44}$; pero ni de la falta de ellas ni de los problemas administrativos a los que se alude, se desprende necesariamente que debía ponerse término a un modelo de trabajo que intentaba entregar a los municipios la capacidad para determinar sus propias prioridades en materia de seguridad, contando para ello con recursos transferidos desde el gobierno. La razón principal del nuevo diseño parece estar en la fundada convicción de que una focalización de las intervenciones en áreas más pequeñas podía tener efectos a corto plazo respecto de las tasas de victimización que el gobierno deseaba reducir.

La evidencia internacional indica que una concentración del accionar policial en áreas calientes ("hot spots") puede tener efectos significativos respecto del delito ${ }^{45}$. Por otra parte, es razonable pensar que incluso los programas preventivos puedan focalizarse en áreas pequeñas como son los barrios. Desde una perspectiva financiera y administrativa, la creación del nuevo programa tenía la ventaja adicional de enfocar recursos escasos en áreas pequeñas, en vez de dispersarlos en comunas populosas, como sucedía con el Programa de Seguridad Comunal del gobierno previo.

El gobierno decidió centrar el programa en dos tipos de barrios: comerciales y residenciales. La distinción entre barrios comerciales y residenciales

44 Olavarría, M., 2010.

45 Braga A. y Weisburd D., 2010 
parece sensata, dado que los primeros probablemente concentren en su espacio un elevado número de delitos contra la propiedad, por tratarse de áreas que ofrecen importantes oportunidades para delinquir, mientras que en las segundas se acumulan los problemas delictivos que son propios de la segregación residencial a la que nos referimos antes. La selección de las zonas comerciales a intervenir y la definición de la zona a intervenir involucran al Ministerio del Interior, al Gobernador Provincial respectivo y a ambas policías.

La problemática de los barrios comerciales se aborda a través de actividades de control y, eventualmente, de intervenciones en el espacio público que prevengan la ocurrencia de delitos. Para ello, se realiza una caracterización situacional, socialcomercial y delictual del barrio seleccionado con el fin de establecer los principales factores que favorecen la ocurrencia de delitos. En este sentido, se observan y especifican las características y condiciones físicas y sociales que favorecen las oportunidades para la comisión de delitos y la percepción de temor de los ciudadanos. Por otra parte, a través de la georreferenciación, se identifican aquellos lugares que concentran la actividad delictual, observando y determinando las circunstancias espaciales que contribuyen a dicha concentración.
El año 2010 se intervinieron 60 barrios comerciales mientras que en 2011 comenzaron otras ocho intervenciones adicionales. Los resultados que se esperan son la reducción de la victimización por delitos de oportunidad; la reducción de factores de riesgo situacionales presentes en cada barrio y una mejora en la tasación del suelo en las zonas comerciales y que se fortalezca la relación entre los locatarios y la autoridad ${ }^{46}$.

Mediante la utilización de un enfoque que complementa los aspectos de prevención situacional, con el control policial y la colaboración entre comerciantes y la autoridad, el programa buscará impactar en tasas de victimización y denuncias, además de lograr mejoras sustanciales en materia de inversión urbana.

\section{BARRIO EN PAZ RESIDENCIAL: OBJETIVOS DEL PROGRAMA Y SELECCIÓN DE LOS BARRIOS A INTERVENIR}

El Programa Barrio en Paz enfocado en barrios residenciales persigue objetivos distintos de aquellos que corresponden a Barrio en Paz Comercial, ya que se trata, en este caso, de barrios con altos niveles de incivilidades y desorden social, bajo apego por la legalidad, prevalencia de violencia interpersonal, que a la vez son el lugar de residencia de un número elevado de personas involucradas en

46 Gobierno de Chile, Modelo conceptual Programa Barrio en Paz. Marzo 2011. Págs. 15-19. 
actividades criminales, especialmente relacionadas con drogas ilícitas ${ }^{47}$.

La propuesta del gobierno implica una intervención en un número bastante elevado de estos barrios, que llegaría a 100 en el curso de cuatro años. Inicialmente se incorporaron 18 barrios en julio del año 2010, para luego sumar 32 adicionales en abril de 2011. Como puede verse, el objeto de las intervenciones son barrios de características similares a los barrios intervenidos a través del Programa Barrio Seguro, ya que en ellos se ha instalado la venta de drogas y, a la vez, es posible detectar una concentración de factores de riesgo que resultan en problemas delictuales o de violencia ${ }^{48}$. Sin embargo, a diferencia de Barrio Seguro, la intervención en barrios se constituye ahora en el foco central de la política gubernamental y ella busca reducir los problemas delictuales no sólo en esos barrios, sino que en el conjunto del país. De allí que los criterios utilizados para seleccionar los barrios en los que se realizarían las intervenciones resultan cruciales.

A ese respecto, dos factores inciden fuertemente en la selección de los barrios a intervenir: el primero es que no existen indicadores relativos a

47 Unidad de Prevención, División de Seguridad Pública del Minis terio del Interior, 2011.

48 Subsecretaría de Prevención del Delito de Chile. Plan de seguridad pública 2010 - 2014. Ejes transversales. [En línea] Junio de 2010. [Fecha de consulta: 07 de junio de 2011] Disponible en: http://www.seguridadpublica.gov.cl/ejes_transversales_-plan_de_seguridad_publica_201.html.

166 revista invi № 74 / Mayo 2012 / Volumen № 27: 149-185 victimización y a variables que expresen factores de riesgo a nivel de barrios, lo que obliga a recurrir a información obtenida a nivel de municipios. El segundo es de carácter político: esto es, que la determinación del barrio a intervenir involucra un acuerdo del Ministerio con el Alcalde respectivo, de manera que éste colabore con los recursos institucionales del municipio en la realización de los programas de mejoramiento del barrio. Naturalmente, esa negociación puede llevar a que se seleccionen barrios por razones diferentes a su índice objetivo de violencia o de producción de infractores de ley.

El proceso de selección de barrios residenciales considera también el número de habitantes de los municipios y la llamada variable delictual. La determinación de los municipios de donde se seleccionarían los barrios ya no toma en cuenta variables de vulnerabilidad social, como en el Programa Comuna Segura.

El método de selección fue el siguiente: se procedió a seleccionar a todas las comunas sobre 25 mil habitantes. Enseguida, se construyó un índice compuesto de distintos indicadores asociados a actividad delictual y victimización registrados en 
la comuna. Para ello, se tomaron en cuenta las estadísticas de: i) denuncias y detenciones por robo o hurto de vehículo, robo o hurto desde vehículo, robo con fuerza en vivienda, robo por sorpresa a las personas, robo con violencia o intimidación, lesiones, homicidio y violación proporcionadas por la base de datos de Carabineros del año 2009; ii) detenidos por la participación en los delitos nombrados anteriormente durante el año 2009 en la comuna; iii) procedimientos de drogas del año 2009, y iv) victimización de los habitantes en la comuna según datos de la Encuesta de Victimización del año $2009^{49}$. En la construcción de este índice la mayor ponderación se otorgó a la tasa de frecuencia de detenidos por la comisión de los delitos mencionados y a la tasa de procedimientos policiales por drogas, lo que es coherente con la definición del programa como centrado en "barrios críticos", donde residen numerosos infractores de la ley, más que en barrios donde ocurren muchos delitos.

El paso siguiente consistió en la priorización de las comunas de donde se seleccionarían los barrios

49 Subsecretaría de Prevención del Delito de Chile. VI Encuesta Nacional Urbana de Seguridad Ciudadana. [En línea] 2009. [Fecha de consulta: 02 de noviembre de 2011] Disponible en: http:// www2.dsp.gov.cl/files/00_presentacion_enusc_2009_pais. pdf para efectuar las intervenciones. Por razones que pueden tener que ver con su visibilidad o importancia política, pero no con criterios o razones criminológicas, se otorgó un $60 \%$ de ponderación a la población de la comuna y solo un $40 \%$ al indicador delictual ${ }^{50}$. Esto naturalmente beneficiaba a los municipios de mayor población.

A partir de la determinación de las comunas consideradas prioritarias, se seleccionaron los barrios, que no podían superar 10.000 habitantes y que debían tener continuidad territorial. Estos criterios ciertamente facilitaban el trabajo a realizar. Tales barrios eran seleccionados de común acuerdo entre el Ministerio del Interior y el alcalde respectivo.

Como puede verse, la selección de los barrios era precedida por una selección previa de los municipios, en la que primaba la consideración de su población por sobre consideraciones delictuales o de vulnerabilidad social. Esto ha llevado a que solo uno de los barrios que formaron parte de Barrio Seguro fuera incluido en el Programa Barrio en Paz Residencial ${ }^{51}$.

50 Unidad de Prevención, División de Seguridad Pública del Ministerio del Interior, 2011, p. $20-21$.

51 Un caso muy especial es el de La Legua Emergencia, barrio para el cual el gobierno actual diseñó un programa específico a pedido del alcalde, los vecinos y el párroco local, debido a los niveles de violencia existentes entre bandas locales. Ello, a pesar de que inicialmente no formó parte de los barrios a intervenir. Ver al respecto; “Vecinos de La Legua Temerosos ante el Renacer de la Violencia entre Narcos", El Mercurio, 30 de octubre de 2011, p. C14. 


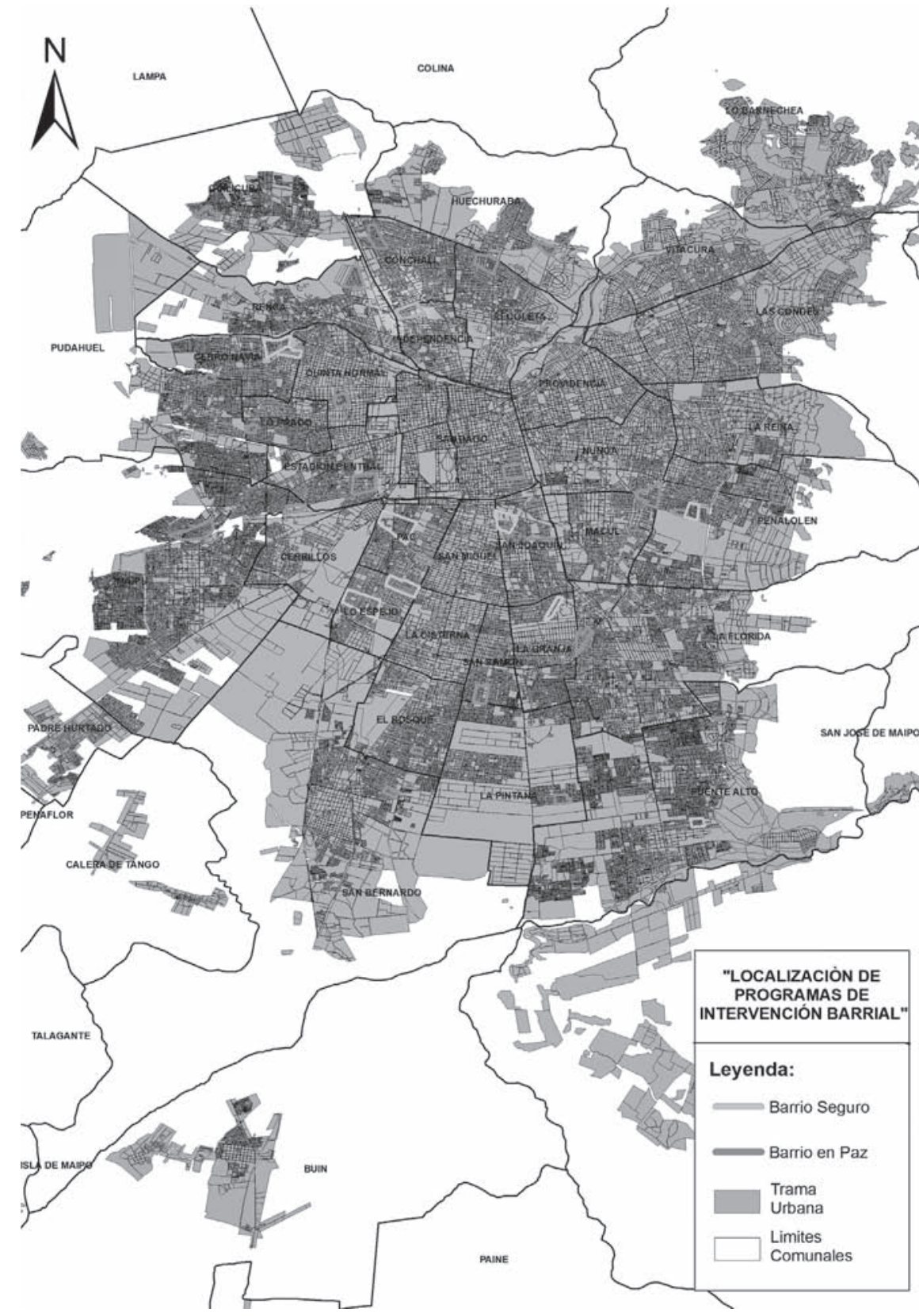

FIGURA 1 MAPA DE PROGRAMAS BARRIO SEGURO Y BARRIOS EN PAZ

Fuente: Elaboración propia desde información de la Subsecretaría de Prevención del Delito de Chile.
168 revista invi № 74 / Mayo 2012 / Volumen № 27: 149-185 
En el siguiente mapa, se observa la situación descrita. En color verde aparecen barrios intervenidos del Programa Barrio Seguro (BS), en color rojo los barrios intervenidos actualmente por el Programa Barrio en Paz Residencial (PBEPR):

Tan solo el barrio Sara Gajardo, ubicado en la comuna de Cerro Navia, ha sido intervenido en ambos programas. Sin embargo, existe cercanía entre algunos barrios intervenidos a través de Barrio Seguro y otros intervenidos a través de Barrio en Paz Residencial.

\section{Líneas de Intervención de Barrios en Paz Residencial}

A diferencia de lo que ocurría con Barrio Seguro, en este Programa no se han definido líneas de intervención pre establecidas, ya que éstas dependen del resultado del diagnóstico del barrio que le corresponde realizar al coordinador municipal respectivo. El Manual de Caracterización de Barrios refiere los ámbitos respecto de los cuales sería factible realizar la intervención respectiva. Estos son: ámbito de niños y niñas en situación de vulnerabilidad; ámbito de consumo de drogas y alcohol; ámbito escolar; ámbito comunidad; ámbito laboral; ámbito de reinserción social y ámbito situacional ${ }^{52}$. En relación con cada uno de esos ámbitos se requiere realizar previamente un catastro de los proyectos que podrían aportar una oferta programática destinada a enfrentar el problema respectivo.

52 Ministerio del Interior, 2010, p. 3.
Las directrices del Programa indican que la intervención preventiva no se aplica sobre la totalidad de la población del barrio, ni sobre la totalidad de sus viviendas ${ }^{53}$. La determinación de los focos prioritarios de acción gubernamental forma parte de un diagnóstico comunitario que involucra la búsqueda de información relevante a través de una metodología cualitativa, que consulta entrevistas con vecinos y con actores institucionales instalados en el territorio.

Las entrevistas realizadas permiten detectar algunas ambigüedades en la implementación de la intervención, que tienen su origen en el proceso de selección de los barrios a intervenir. En efecto, los diagnósticos levantados cualitativamente indican en ocasiones que los vecinos distan de considerar el barrio seleccionado como un barrio crítico en el que primen altos niveles de temor. Por otra parte, encuestas realizadas por la Fundación Paz Ciudadana en 10 de los barrios donde se inició el Programa Barrio en Paz Residencial en el 2010, revelan bajos niveles de victimización en el barrio ${ }^{54}$, aunque elevada percepción de desorden social, de uso de armas y disputas violentas en el espacio público.

Entonces, el programa se encuentra con ciertos casos en que la victimización e inseguridad de los habitantes de los lugares que se pretenden abordar, no poseen la relevancia necesaria como para justificar

53 Ibíd. p. 23.

54 Trujillo L. y Arévalo J. P., 2011. 
una focalización del accionar policial en el lugar, aunque ésta podría ser necesaria para enfrentar la presencia de narcotráfico. El impacto de esa intervención policial dirigida al narcotráfico respecto de las tasas generales de victimización de la ciudad no es conocido. Por otra parte, el tipo de problemas que sí se presentan requieren de un diagnóstico adecuado respecto de los factores que les dan origen, y de intervenciones innovadoras que probablemente superan la oferta de programas existentes en el país. Un caso claro es el de las disputas violentas en el espacio público cuyo origen y solución pueden ser múltiples. Eventualmente se pueden enfrentar con programas de mediación vecinal, con programas dirigidos a pandillas, o con patrullaje policial dirigido a evitar el consumo de alcohol en la vía pública.

No es posible examinar aún la implementación de Barrio en Paz Residencial, puesto que ésta es demasiado reciente y en algunos casos las transferencias de fondos y en otros el inicio de proyectos se han retrasado. La Dirección de Presupuestos del Ministerio de Hacienda ha encargado muy recientemente una evaluación del programa. La observación en terreno y conversación con operadores señala que existe claridad respecto de los componentes de prevención situacional y de prevención psicosocial comprendidos en el programa y

170 revista invi № 74 / Mayo 2012 / Volumen № 27: 149-185 plenamente descritos en los manuales producidos por la División de Seguridad Pública. Sin embargo, no existe la misma claridad respecto del componente de control policial de ese Programa y de su relación con las actividades preventivas.

La actividad de control debiera dirigirse hacia la presencia de narcotráfico y de riñas y otras manifestaciones de violencia en el territorio, ya que como se ha indicado la victimización no parece ser muy alta en los barrios seleccionados. El documento descriptivo del Programa desarrolla conceptos relativos a la necesidad de mejorar la tarea de inteligencia en los barrios a fin de neutralizar las redes de microtráfico que allí se afincan y sostiene, asimismo, que resulta imperativo mejorar la relación entre Carabineros y el público de esos barrios, a fin de obtener mayor información que permita neutralizar esas redes criminales ${ }^{55}$. Más allá de esas observaciones generales el enfoque de control no parece sustentar estrategias particularmente innovadoras en el contexto de barrios críticos, como de acuerdo con las evaluaciones se requiere para enfrentar fenómenos como el tráfico de drogas ${ }^{56}$.

Desde la perspectiva de la policía, parece existir la percepción de que se les ocupa únicamente como una herramienta para el ejercicio del control en los territorios intervenidos. Si bien ésta es una de

55 Unidad de Prevención, División de Seguridad Pública del Ministerio del Interior, 2011.

56 Mazerolle, L., Soole, D. y Rombouts, 2006, p. 409-435. 
las tareas principales tanto de Carabineros como de la Policía de Investigaciones de Chile, existen otras capacidades en ambas instituciones que no han sido utilizadas desde los gobiernos centrales, no considerándolas como actores relevantes de la discusión con las autoridades municipales acerca de las estrategias y la gestión de recursos en los procesos de intervención.

\section{Evaluación DE LAS INTERVENCIONES}

Uno de los avances que presenta el Programa Barrio en Paz con respecto de los programas antes descritos, es que se ha establecido una línea de base que permitiría contrastar la situación inicial del barrio en materia de victimización, temor al delito y percepción de sus habitantes y contrastarla con avances que podría experimentar con el transcurso del tiempo. Esta línea de base es aplicable a todas aquellas intervenciones cuyos resultados pueden ser percibidos por los habitantes de la comuna.

Para los efectos de medir el avance de cada programa o proyecto, un Programa como Barrio en Paz Residencial puede establecer metas simples, adecuadas y significativas para quienes operan los programas de manera de establecer si éstos tienen efecto. Puede tratarse de disminuir los índices de reincidencia de los adultos que egresan de la cárcel y que viven en el barrio, o disminuir la prevalencia del consumo de drogas entre adolescentes residentes.
Pero en definitiva, el bienestar de un barrio no puede medirse a través de índices de victimización, ya que tales adolescentes y adultos pueden actuar o delinquir en otros barrios. Ello obliga a definir indicadores más sofisticados que permitan condensar el objetivo último de todas las intervenciones y comparar avances entre diversos barrios intervenidos y con respecto de aquellos con características similares y que no lo fueron. Aspectos tales como el temor de la población frente al delito, los niveles de confianza interpersonal y la desaparición de incivilidades y desorden social debieran considerarse, en un proceso de reflexión que llevara a la definición de indicadores relevantes para los objetivos del programa.

Estos indicadores deberían combinarse en la constitución de un índice de seguridad residencial en barrios críticos, que permitiría analizar la evolución en el tiempo de estas intervenciones y comparar el éxito de las intervenciones entre diversos de los barrios beneficiados por el programa.

En este ámbito, evidencia reciente se orienta a proponer el desarrollo de estudios de carácter longitudinal que acompañen estas intervenciones con el objeto de observar cómo se comportan las variables involucradas a lo largo del tiempo y, de esta forma, los Programas puedan tener un proceso constante de alimentación que colabore en adecuaciones constantes y oportunas a las realidades en las que se 
ejecutan ${ }^{57}$. La información levantada debiera tener carácter público, lo que puede facilitar el debate informado en materia de políticas dirigidas a barrios.

Es importante indicar, adicionalmente, que el aporte que la intervención Barrio en Paz Residencial podría hacer a las metas que se ha fijado el gobierno actual no está enteramente claro. A diferencia del Programa Barrio Comercial, en estos barrios no parecen concentrarse muchos delitos con víctimas y, en consecuencia, su impacto respecto de la tasa de victimización general o de la tasa de victimización en el espacio público de delitos contra la propiedad depende de que las intervenciones preventivas y el accionar policial contra focos de venta de drogas puedan producir disminuciones en la tasa de victimización general. La pregunta a responder en la práctica es si la persecución criminal centrada en los puntos de venta de drogas conducirá a una disminución de otros delitos, cumpliendo por tanto, con un objetivo más general de seguridad pública ${ }^{58}$.

\section{Conclusiones y Recomendaciones}

La focalización de los recursos disponibles para control y prevención del delito en puntos calientes, donde se concentran hechos criminales o en lugares donde existen factores sociales que pueden

57 Trujillo L. y Arévalo J. P., 2011.

58 Ver al respecto Foglesong, T. y Stone, C., 2007, p. 27- 30. incentivar el desarrollo de carreras criminales, encuentra sustento en la literatura.

Desde esa perspectiva el caso chileno es interesante, porque en respuesta al incremento del delito y del temor al delito en años recientes, se han venido realizando programas desde el gobierno central que focalizan recursos y capacidad técnica en municipios y áreas más pequeñas como los barrios, con fines de prevención y de control que se dirigen a reducir la manifestación de hechos criminales e impedir que se desarrollen carreras criminales. La cobertura de estos programas ha sido considerable, llegando a abarcar a alrededor de un tercio de los municipios de Chile en el caso de Comuna Segura. A su vez, el Programa Barrio en Paz en sus dos vertientes: Barrio en Paz Comercial y Barrio en Paz Residencial llegará paulatinamente a cubrir 160 barrios, correspondientes a otros tantos municipios.

Desde la perspectiva de la prevención, una atención preferente a barrios donde parece existir bajo apego a la legalidad y donde se acumulan factores de vulnerabilidad social, o de donde provienen infractores de la ley está plenamente justificada. De hecho, tanto Comuna Segura como Barrio en Paz Residencial han concentrado recursos técnicos y financieros en crear o fortalecer la oferta programática en ese sentido. La experiencia de diez años ha conducido a la formación de recursos humanos 
en el área de prevención, a un diseño cada vez más acotado de los programas y a una mejor precisión de sus objetivos. En el caso de Comuna Segura, se pasó de la transferencia de recursos vía fondos concursables que trajo consigo dispersión de proyectos y escaso impacto de los mismos, a la entrega de recursos mediante los llamados Fondos de Ayuda a la Gestión Municipal que debían aplicarse en función de Planes Comunales de Seguridad.

A su vez, en materia de barrios, se pasó de intervenciones esporádicas concentradas en los llamados "barrios emblemáticos" del Programa Barrio Seguro, que fueron sólo doce barrios, a un Programa más estructurado que focaliza las intervenciones en barrios comerciales donde se concentra la ocurrencia de delitos y en barrios residenciales, que revisten las características críticas que mencionábamos antes. Existe un avance también, en cuanto el Programa Barrio en Paz Residencial establece límites de población y extensión a los barrios objeto de intervención, además de establecer que éstos deben contar con población estable y tener plena continuidad en su trama urbana.

Tanto Comuna Segura como Barrio en Paz contaban con criterios conocidos de selección, lo que contribuye a dar transparencia a las decisiones. Sin embargo, en los tres programas analizados es posible encontrar problemas en la selección de las áreas donde se ejecutan las intervenciones respectivas. En el caso de Comuna Segura no estaba disponible información respecto de las áreas críticas de residencia de infractores de ley, que podría haber colaborado en la selección de los lugares donde deberían realizarse los programas preventivos.

En el caso de Barrio Seguro los indicadores utilizados para la selección de las doce poblaciones intervenidas no eran públicos. Por último, en el caso de Barrio en Paz Residencial la selección de barrios era precedida del uso de información delictual de nivel municipal y no barrial, y la determinación del área de intervención suponía un acuerdo previo con el alcalde respectivo. De allí que no pueda decirse con certeza que los barrios seleccionados son efectivamente aquellos donde la intervención pública tendría un efecto más significativo.

Ello puede explicar que los barrios seleccionados en esta primera etapa de Barrio en Paz Residencial coincidan muy parcialmente con los que formaron parte del Programa Barrio Seguro. Ello en particular llama la atención en el caso del barrio La Legua Emergencia, que por presión de vecinos y del municipio respectivo hubo de ser incorporado a un programa específico en una etapa posterior.

Un segundo aspecto que se desprende de la información reunida, es que las intervenciones de control, especialmente las de carácter policial dirigidas al microtráfico no parecen haber obtenido los resultados esperados, al menos en las poblaciones más peligrosas. Así mismo, desde la perspectiva de la política pública, una pregunta pertinente es 
la medida en que esas intervenciones policiales enfocadas en microtráfico de drogas, uso de armas y delitos menores en barrios críticos pueden reducir la victimización del tipo de delitos que el gobierno actual se ha puesto como meta. Es posible que la calidad de vida en los llamados barrios críticos mejore, pero no existe aún evidencia que demuestre que esas acciones de control tendrán efecto benéfico respecto de otro tipo de delitos (robos con violencia, robos simples, hurtos, robos de vehículos o de objetos desde vehículos, por ejemplo) que ocurren en otras áreas de la ciudad.

En materia de los programas preventivos que se ejecutan, la información proveniente de la encuesta realizada en el marco de esta investigación parece especialmente relevante por entregar información representativa del Gran Santiago que permite hacer estimaciones sobre barrios del Gran Santiago donde los ciudadanos dicen percibir la presencia de narcotráfico, desorden social en el espacio público y bajo apego a la legalidad. Dicha encuesta parece sustentar evidencia de que los programas dedicados a la movilización comunitaria pueden cumplir fines muy positivos, pero parece improbable que reduzcan el delito.

Es a partir de estas conclusiones que recomendamos que el desarrollo del Programa Barrio en Paz construya indicadores claros y conocidos a nivel barrial, que permitan comparar la realidad barrial en materia de seguridad de manera de asegurar un proceso de selección de barrios que pueda redundar en resultados efectivos. Sin algún tipo de definición de los barrios, tampoco será posible comparar el efecto de las intervenciones con barrios de control para medir el impacto efectivo de las intervenciones. En la actualidad se utilizan en una primera etapa indicadores de acción policial y de victimización a nivel municipal, lo que dificulta la selección de los barrios que efectivamente poseen mayores niveles de inseguridad, o que cuentan con un stock más elevado de infractores de ley.

Creemos necesario diseñar un índice de seguridad por barrios, que dé cuenta tanto de información delictual objetiva como de percepciones respecto de la ocurrencia de hechos de violencia o incivilidades en el espacio público, el que debiera ser de conocimiento público.

En lo referente a intervenciones de control realizadas por la policía y el Ministerio Público en este tipo de barrios, es importante realizar evaluaciones de impacto de las mismas, pero también evaluaciones cualitativas respecto de las tácticas utilizadas, y la percepción de los residentes a su respecto, de manera de aportar a políticas de control efectivas en el contexto de barrios críticos.

Por último, las intervenciones en barrios requieren de la aplicación de instrumentos que recojan información adecuada sobre las dinámicas sociales que tienen lugar en su interior y que hacen sustentables los programas que allí se ejecutan, sin la cual éstas tendrán un reducido éxito. 


\section{ANEXO A}

\section{ANÁLISIS DE LA ENCUESTA APLICADA EN ESTE ESTUDIO}

Se aplicó una encuesta en una muestra de barrios del GS entre el 01 de agosto al 03 de octubre de 2010. Fueron seleccionados mediante procedimientos probabilísticos 242 barrios del GS, representativos del total de barrios del territorio en estudio ${ }^{59}$. Este instrumento fue de tipo presencial, siendo las unidades de análisis personas, hogares, barrios y unidades vecinales de cada uno de los barrios seleccionados. La muestra consideró a 5.861 personas, habitantes de los 242 barrios seleccionados, y contó con un margen de error de +/- 1,3\%. A su vez, la muestra fue ponderada según peso proporcional por Grupo Socioeconómico predominante de los barrios, como también por sexo y edad. Por último, el contacto se realizó con personas que vivieran de forma permanente en las viviendas elegidas dentro de cada barrio y que tuviesen 15 o más años de edad.

En cuanto a las variables que se ocuparon para este trabajo en particular, éstas se muestran en el anexo que da cuenta de la operacionalización de los elementos seleccionados del total de variables contenidas en el cuestionario de la encuesta.

59 Los "barrios del Gran Santiago" fueron definidos operacionalmente como 6 manzanas censales en promedio con una distancia en kilómetros relativamente homogénea, lo cual arroja que habrían cerca de 8.000 áreas de similar extensión en el Gran Santiago.
A su vez, como también se observa en la tabla de operacionalización, las categorías de respuestas implican distintos niveles de medición de las variables por lo cual fue necesario homogeneizar la información para así poder utilizar técnicas estadísticas idóneas, como también poder clasificar los barrios para la interpretación de los resultados.

Las variables ingresos mensuales del hogar y años viviendo en el barrio, se obtuvieron directamente de la encuesta. Al igual que con las variables descritas en la tabla que se encuentra en el Anexo anterior, se calcula el promedio por personas de un barrio hasta llegar a clasificar a cada barrio en función de sus ingresos y el promedio de años que han habitado sus habitantes en él. O sea, se consiguen 242 clasificaciones, una por cada barrio, de "ingresos" y "años".

Se efectuó un análisis de índole multivariada en dos etapas. En primer lugar, se realiza un análisis de componentes principales, ya que esta técnica permite extraer nuevas dimensiones que reflejen información latente de las variables originales ${ }^{60}$. Para efectuar este ejercicio, fueron separadas tres variables prioritarias para las políticas públicas de carácter territorial: la "victimización en el barrio", la "victimización producto de uso de la fuerza y

60 Vivanco, M., 1999, p. 96. 


\section{TABLA 1: VARIABLES EN ESTUDIO Y SU USO EN LAS ETAPAS DE ANÁLISIS}

\begin{tabular}{|c|c|c|}
\hline \multirow[t]{2}{*}{ Variables estudiadas } & \multicolumn{2}{|c|}{ Etapas de análisis y tipo de variables } \\
\hline & Etapa 1 & Etapa 2 \\
\hline Victimización en el barrio & & Dependiente \\
\hline Victimización con fuerza o violencia en el barrio & $\longrightarrow$ & Dependiente \\
\hline Percepción de inseguridad en el barrio & & Dependiente \\
\hline Percepción de incivilidades en el barrio & & Nuevos com- \\
\hline Percepción de violencias en el barrio & & ponentes \\
\hline Percepción de probabilidad de ser víctima de algún delito en el barrio & & (variables in- \\
\hline Percepción de ilícitos de drogas en el barrio & & dependientes) \\
\hline Percepción de confrontaciones violentas en el barrio & & \\
\hline Percepción de desórdenes en el barrio & & \\
\hline Apego a la legalidad & & \\
\hline Control social informal & & \\
\hline Ingresos mensuales del hogar & & \\
\hline Promedio de años en el barrio & & \\
\hline
\end{tabular}

Fuente: Elaboración propia desde Encuesta ANILLOS.

violencia en el barrio" y la "percepción de inseguridad en el barrio".

En la tabla 1 se observan las variables utilizadas y su uso en diferentes etapas del análisis:

Como primer paso, excluyendo a victimización e inseguridad, se quiere descubrir las dimensiones contenidas por el resto de las variables en estudio, para de esta forma reducir las dimensiones latentes y poder identificar elementos comunes a ciertos grupos de variables, con el fin de simplificar las posibles observaciones que pueden surgir ${ }^{61}$.

Efectuada la anterior operación, se descubrieron 2 grandes dimensiones que en conjunto explican aproximadamente el $64 \%$ de la varianza de la información contenida en el total de elementos

61 Vivanco, M., 1999 
considerados $^{62}$, estos resultados se observan en las tablas 2 y 3.

A cada una de las dimensiones que surgen se les asignó un nombre ficticio con tal de identificarlas nominalmente. Estas nuevas agrupaciones se designan como componentes y poseen la peculiaridad de ser independientes entre ellas ${ }^{63}$. Se incluye también en las tablas siguientes los pesos factoriales (PF) de cada variable respecto a su componente, lo cual corresponde a la magnitud y sentido en la que cada una de ellas aporta a su dimensión ${ }^{64}$.

Se muestran en primer término las variables que componen la dimensión desventajas barriales, nombre ficticio que se asigna solamente desde la base de los elementos que le conforman:

62 Para este análisis, la medida de adecuación de la muestra KMO corresponde a 0,863 . Este coeficiente permite comparar los coeficientes de correlación observados con los coeficientes de correlación parcial, asumiendo valores entre 0 a 1; se entiende que el modelo es de mejor calidad mientras más se acerque al 1. 63 Vivanco, M., 1999.

64 Los pesos factoriales indican cuánta información aporta cada variable a cada uno de los componentes que surgen del análisis. De esta forma, se espera como escenario ideal que una variable determinada presente una magnitud elevada de peso factorial para un componente "a", y un nivel más bajo para un componente " $b$ ". Esto contribuye a establecer que aquella variable se agrupa de mejor forma a las cualidades que contienen al componente "a". Sin embargo, existen situaciones empíricas, no ideales, en las cuales se recomienda incluir variables en más de un componente con el fin de favorecer interpretaciones posteriores, situación que se observa en las tablas 2 y 3 respecto a la variable Ingresos Mensuales del Hogar.
Por último, se desagregan las variables que conforman la dimensión llamada hábitat, que al igual que el caso anterior corresponde a una denominación artificial a partir de las características que se agrupan en torno a ella:

En siguiente paso del análisis se utilizan estos componentes como nuevas variables que permiten explicar la variación de las variables dependientes que han sido dejadas aisladas previamente: la "victimización en el barrio", la "victimización con uso de fuerza o violencia en el barrio" y la "percepción de inseguridad en el barrio".

Siguiendo con el análisis, se constata que la incidencia de las desventajas barriales es mayor para la "percepción de inseguridadenel barrio" $(0,458)$ que para "tipos de victimización” (0,293 y 0,328, respectivamente). 


\section{TABLA 2: COMPONENTE DESVENTAJAS BARRIALES}

\begin{tabular}{lc} 
Variables que se incluyen en el componente & PF \\
\hline Percepción de violencias en el barrio &, 975 \\
\hline Percepción de ilícitos de drogas en el barrio &, 971 \\
\hline Percepción de confrontaciones violentas en el barrio &, 964 \\
\hline Percepción de incivilidades en el barrio &, 915 \\
\hline Percepción de desórdenes en el barrio &, 855 \\
\hline $\begin{array}{l}\text { Percepción ante probabilidad de ser víctima de } \\
\text { algún delito en el barrio }\end{array}$ &, 568 \\
\hline Apego a la legalidad &,- 417 \\
\hline Ingresos mensuales del hogar &,- 376 \\
\hline
\end{tabular}

Fuente: Elaboración propia desde Encuesta ANILLOS.

\section{TABLA 3: COMPONENTE HÁBITAT}

\begin{tabular}{lc} 
Variables que se incluyen en el componente & PF \\
Promedio de años en el barrio &,- 786 \\
\hline Ingresos mensuales del hogar &, 697 \\
\hline Control social informal &, 386 \\
\hline
\end{tabular}

Fuente: Elaboración propia desde Encuesta ANILLOS.

TABLA 4: REGRESIÓN LINEAL - MODELO EXPLICATIVO

\begin{tabular}{|c|c|c|c|}
\hline \multirow[t]{3}{*}{ Variables independientes } & \multicolumn{3}{|l|}{ Variables dependientes } \\
\hline & Victimización en el barrio & $\begin{array}{l}\text { Victimización por uso de fuer- } \\
\text { za o violencia en el barrio }\end{array}$ & $\begin{array}{l}\text { Percepción de inseguridad } \\
\text { en el barrio }\end{array}$ \\
\hline & Grado de relación & Grado de relación & Grado de relación \\
\hline \multirow[t]{2}{*}{ Desventajas barriales } & ,293 & ,328 & ,458 \\
\hline & 000 &, 000 &, 000 \\
\hline Hábitat & \multicolumn{3}{|c|}{$\begin{array}{l}\text { *No se encuentran asociaciones significativas entre la variable hábitaty las tres depen- } \\
\text { dientes. Se excluye de los modelos propuestos. }\end{array}$} \\
\hline
\end{tabular}

Fuente: Elaboración propia desde Encuesta ANILLOS. 


\section{ANEXO B}

\section{OPERACIONALIZACIÓN DE LAS VARIABLES ANALIZADAS EN LA ENCUESTA APLICADA EN ESTE ESTUDIO}

\begin{tabular}{|c|c|c|c|}
\hline Variable & Pregunta & Indicador & Categorías \\
\hline \multirow[t]{7}{*}{$\begin{array}{l}\text { Victimización en } \\
\text { el barrio }\end{array}$} & \multirow{7}{*}{$\begin{array}{l}\text { ¿Cuántos de esos } \\
\text { delitos ocurrieron } \\
\text { en el barrio don- } \\
\text { de usted vive? }\end{array}$} & $\begin{array}{l}\text { Usted o alguien de su familia ha sido víctima de algún delito } \\
\text { durante los últimos } 12 \text { meses }\end{array}$ & \multirow[t]{7}{*}{ Abierta } \\
\hline & & Delitos violentos & \\
\hline & & Robo con fuerza & \\
\hline & & Robo con violencia & \\
\hline & & Hurtos & \\
\hline & & Lesiones & \\
\hline & & Amenazas & \\
\hline \multirow{4}{*}{$\begin{array}{l}\text { Victimización } \\
\text { producida por } \\
\text { fuerza o violencia } \\
\text { en el barrio }\end{array}$} & \multirow{4}{*}{$\begin{array}{l}\text { ¿Cuántos de esos } \\
\text { delitos ocurrieron } \\
\text { en el barrio don- } \\
\text { de usted vive? }\end{array}$} & Delitos violentos & \multirow[t]{4}{*}{ Abierta } \\
\hline & & Robo con fuerza & \\
\hline & & Robo con violencia & \\
\hline & & Lesiones & \\
\hline \multirow{4}{*}{$\begin{array}{l}\text { Percepción de } \\
\text { inseguridad en el } \\
\text { barrio }\end{array}$} & \multirow{4}{*}{$\begin{array}{l}\text { ¿Qué tan seguro } \\
\text { se siente usted } \\
\text { antes las siguien- } \\
\text { tes situaciones? }\end{array}$} & Caminando solo/a por el barrio de día & \multirow{4}{*}{$\begin{array}{l}\text { Muy inseguro } \\
\text { Inseguro } \\
\text { Ni seguro ni } \\
\text { inseguro } \\
\text { Seguro } \\
\text { Muy seguro }\end{array}$} \\
\hline & & Esperando el transporte público en el barrio & \\
\hline & & Cuando un desconocido ronda por el barrio & \\
\hline & & Caminando solo/a por el barrio cuando anochece & \\
\hline \multirow{7}{*}{$\begin{array}{l}\text { Percepción de } \\
\text { incivilidades en el } \\
\text { barrio }\end{array}$} & \multirow{7}{*}{$\begin{array}{l}\text { ¿Con qué fre- } \\
\text { cuencia ocurren } \\
\text { las siguientes } \\
\text { situaciones en } \\
\text { el barrio donde } \\
\text { usted vive? }\end{array}$} & Rayados que destruyen el entorno & \multirow{7}{*}{$\begin{array}{l}\text { Nunca } \\
\text { Casi nunca } \\
\text { A veces } \\
\text { Casi siempre } \\
\text { Siempre }\end{array}$} \\
\hline & & Uso de lenguaje agresivo y grosero en la vía pública & \\
\hline & & $\begin{array}{l}\text { Daños menores a la infraestructura pública como semáforos, } \\
\text { alumbrado, canchas u otras }\end{array}$ & \\
\hline & & $\begin{array}{l}\text { Apropiación de plazas o sitios eriazos por grupos que provo- } \\
\text { can desórdenes }\end{array}$ & \\
\hline & & Consumo de alcohol o drogas en la vía pública & \\
\hline & & Acumulación de basura y falta de higiene en el entorno & \\
\hline & & Ruidos molestos (música alta, gritos, bullicio) & \\
\hline
\end{tabular}




\begin{tabular}{|c|c|c|c|}
\hline Variable & Pregunta & Indicador & Categorías \\
\hline $\begin{array}{l}\text { Percepción de } \\
\text { violencias en el } \\
\text { barrio }\end{array}$ & $\begin{array}{l}\text { ¿Con qué fre- } \\
\text { cuencia ocurren } \\
\text { las siguientes } \\
\text { situaciones en } \\
\text { el barrio donde } \\
\text { usted vive? }\end{array}$ & $\begin{array}{l}\text { Amenazas verbales y agresiones contra los transeúntes } \\
\text { Asaltos a transeúntes con violencia o intimidación } \\
\text { Amenazas y riñas entre grupos o bandas } \\
\text { Apropiación de espacios públicos por personas/grupos que } \\
\text { se dedican a cometer delitos y/o al tráfico de drogas } \\
\text { Destrucción de la propiedad privada (vehículos, casas o co- } \\
\text { mercio) por personas/grupos } \\
\text { Destrucción de la infraestructura pública (semáforos, alum- } \\
\text { brado, plazas, canchas u otras) por personas/grupos } \\
\text { Venta ilegal de alcohol (lugares clandestinos) } \\
\text { Robos en viviendas, negocios o en vehículos estacionados } \\
\text { Producción, distribución y/o venta de drogas } \\
\text { Enfrentamientos entre grupos o bandas con uso de armas } \\
\end{array}$ & $\begin{array}{l}\text { Nunca } \\
\text { Casi nunca } \\
\text { A veces } \\
\text { Casi siempre } \\
\text { Siempre }\end{array}$ \\
\hline $\begin{array}{l}\text { Percepción ante } \\
\text { probabilidad de } \\
\text { ser víctima de } \\
\text { algún delito en el } \\
\text { barrio }\end{array}$ & $\begin{array}{l}\text { ¿Cuán probable } \\
\text { es que usted o } \\
\text { alguien de su } \\
\text { hogar sea víctima } \\
\text { de algunos de los } \\
\text { siguientes delitos } \\
\text { en los próximos } \\
\text { doce meses? }\end{array}$ & $\begin{array}{l}\text { Amenazas de personas o grupos } \\
\text { Asaltos (robos con violencia o intimidación) } \\
\text { Robo de vehículo o de objetos dentro de vehículo } \\
\text { Robos en la vivienda } \\
\text { Agresión física o lesiones provocadas por uso de armas } \\
\text { (blanca o de fuego) }\end{array}$ & $\begin{array}{l}\text { Muy } \\
\text { improbable } \\
\text { Improbable } \\
\text { Poco probable } \\
\text { Probable } \\
\text { Muy probable }\end{array}$ \\
\hline $\begin{array}{l}\text { Percepción de } \\
\text { ilícitos de drogas } \\
\text { en el barrio }\end{array}$ & $\begin{array}{l}\text { ¿Con qué fre- } \\
\text { cuencia ocurren } \\
\text { las siguientes } \\
\text { situaciones en } \\
\text { el barrio donde } \\
\text { usted vive? }\end{array}$ & $\begin{array}{l}\text { Consumo de alcohol o drogas en la vía pública } \\
\text { Apropiación de espacios públicos por personas/grupos que } \\
\text { se dedican a cometer delitos y/o al tráfico de drogas } \\
\text { Producción, distribución y/o venta de drogas }\end{array}$ & $\begin{array}{l}\text { Nunca } \\
\text { Casi nunca } \\
\text { A veces } \\
\text { Casi siempre } \\
\text { Siempre }\end{array}$ \\
\hline
\end{tabular}




\begin{tabular}{|c|c|c|c|}
\hline Variable & Pregunta & Indicador & Categorías \\
\hline $\begin{array}{l}\text { Percepción de } \\
\text { confrontaciones } \\
\text { violentas en el } \\
\text { barrio }\end{array}$ & $\begin{array}{l}\text { ¿Con qué fre- } \\
\text { cuencia ocurren } \\
\text { las siguientes } \\
\text { situaciones en } \\
\text { el barrio donde } \\
\text { usted vive? }\end{array}$ & $\begin{array}{l}\text { Asaltos a transeúntes con violencia o intimidación } \\
\text { Amenazas y riñas entre grupos o bandas } \\
\text { Enfrentamientos entre grupos o bandas con uso de armas }\end{array}$ & $\begin{array}{l}\text { Nunca } \\
\text { Casi nunca } \\
\text { A veces } \\
\text { Casi siempre } \\
\text { Siempre }\end{array}$ \\
\hline $\begin{array}{l}\text { Percepción de } \\
\text { desórdenes en el } \\
\text { barrio }\end{array}$ & $\begin{array}{l}\text { ¿Con qué fre- } \\
\text { cuencia se reali- } \\
\text { zan las siguientes } \\
\text { actividades en los } \\
\text { espacios públicos } \\
\text { del barrio? }\end{array}$ & $\begin{array}{l}\text { Venta y consumo de drogas } \\
\text { Comercio ilegal (venta de piratería, artículos robados, otros }\end{array}$ & $\begin{array}{l}\text { Nunca } \\
\text { Casi nunca } \\
\text { A veces } \\
\text { Casi siempre } \\
\text { Siempre }\end{array}$ \\
\hline $\begin{array}{l}\text { Apego a la } \\
\text { legalidad }\end{array}$ & $\begin{array}{l}\text { ¿Cuán de acuer- } \\
\text { do está con } \\
\text { las siguientes } \\
\text { afirmaciones? }\end{array}$ & $\begin{array}{l}\text { Las leyes y normas existen para ser respetadas } \\
\text { Para surgir en la vida, a veces hay que hacer cosas que están } \\
\text { fuera de la ley } \\
\text { No estaría dispuesto(a) a violar las leyes aunque me genera- } \\
\text { ra una retribución económica } \\
\text { Está bien desobedecer las leyes o normas cuando éstas son } \\
\text { injustas } \\
\text { En algunos casos se justifica robar }\end{array}$ & $\begin{array}{l}\text { Muy en } \\
\text { desacuerdo } \\
\text { Desacuerdo } \\
\text { Indiferente } \\
\text { De acuerdo } \\
\text { Muy de } \\
\text { acuerdo }\end{array}$ \\
\hline $\begin{array}{l}\text { Control social } \\
\text { informal }\end{array}$ & $\begin{array}{l}\text { ¿Cuán probable } \\
\text { es que sus veci- } \\
\text { nos intervengan } \\
\text { en las siguientes } \\
\text { situaciones del } \\
\text { barrio? }\end{array}$ & $\begin{array}{l}\text { Cuando niños o jóvenes hacen la cimarra y se quedan en } \\
\text { esquinas o plazas } \\
\text { Cuando un vecino anda por las calles en evidente estado de } \\
\text { ebriedad } \\
\text { Cuando se dé una pelea frente a su casa } \\
\text { Cuando un vecino grita o golpea a su hijo en público } \\
\text { Cuando hay vecinos que botan basura o dañan mobiliario } \\
\text { urbano } \\
\text { Cuando hay venta o consumo de drogas en espacios públicos } \\
\text { Cuando hay un desconocido intentando robar a algún vecino }\end{array}$ & $\begin{array}{l}\text { Muy } \\
\text { improbable } \\
\text { Improbable } \\
\text { Indiferente } \\
\text { Probable } \\
\text { Muy probable }\end{array}$ \\
\hline
\end{tabular}




\section{Bibliografía}

ARAYA, Jorge y SIERRA, David. Influencia de factores de riesgo social en el origen de conductas delincuenciales. Índice de vulnerabilidad socialdelictual. Serie de estudios, División de seguridad ciudadana, Ministerio del Interior. Santiago, Chile, 2002

ARAYA, Jorge. Índice de vulnerabilidad social delictual. Santiago, Chile, Unidad de Estudios División de Seguridad Pública del Ministerio del Interior. 2009

ASESORÍAS PARA EL DESARROLLO. Evaluación de experiencias en La Legua y La Victoria. Informe Fase Cualitativa. Santiago, Chile, Sin publicar. 2003.

BEYER, Harald y VERGARA, Rodrigo. Delincuencia en Chile: Determinantes y rol de las políticas públicas. Santiago, Chile, Pontificia Universidad Católica. 2006. 28 p.

BLOCK, R. Community, environment, and violent crime. Criminology. (17): 46-57. 1979. ISSN 17459125.

BRAGA, Anthony y WEISBURD, David. Editors' Introduction: Empirical Evidence on the Relevance of Place in Criminology. Journal of Quantitative Criminology 2: 1-6. 2010. ISSN 1573- 7799.

BRAGA, Anthony y WEISBURD, David. Policing Problem Places: Crime Hot Spots and Effective Prevention (Studies in Crime and Public Policy).
Nueva York, Estados Unidos, Oxford University Press. 2010. 312 p. ISBN: 9780195341966.

CÁCERES, Gonzalo y SABATINI, Francisco (editores). Barrios cerrados en Santiago de Chile: entre la exclusión y la integración residencial. Santiago, Chile, Lincoln Institute of Land Policy / Instituto de Geografía, Pontificia Universidad Católica de Chile. 2004.

CORPORACIÓN VISIONARIOS POR COLOMBIA. Antípodas de la violencia. Ciudades latinoamericanas descubriendo la corresponsabilidad. Bogotá, Colombia, sin publicar. 2010.

EISSMANN, Ignacio y LUNECKE, Alejandra. Violencia en barrios vulnerables: una aproximación desde la exclusión social. Persona y Sociedad 19 (1): 73-100. 2005.

FOGLESON, Todd y STONE, Christopher. Measuring the Contribution of Criminal Justice Systems to the Control of Crime and Violence: Lessons from Jamaica and the Dominican Republic. Boston, Estados Unidos, Center for International Development at Harvard University, Working Paper No. 144. 2007.

FREY, Antonio. Situación Delictual en Comunas del Gran Santiago DMCS y Drogas en Base a Estadísticas Policiales y Encuestas de Victimización. Santiago, Chile, Nota Técnica preparada para el proyecto Crimen y Violencia Urbana. Aportes de la Teoría Ecológica del Delito al Diseño de Políticas Públicas. 12 p. 2009. 
FRÜHLING, Hugo y SANDOVAL, Luis. Distribución espacial de la actividad delictual en el Gran Santiago: algunos factores explicativos. Estudios Sociales (90): 137-159. 1996. ISSN 0123-885X.

FRÜHLING, Hugo. Políticas públicas en materia de Seguridad Ciudadana durante el Gobierno de Sebastián Piñera (2010-2011). Revista de Ciencia Política 49(2): 113-126. 2011. ISSN 0718-090X.

JOFRÉ, René. La experiencia de la institucionalidad en seguridad ciudadana: el caso chileno. En: ESCOBAR, Santiago y ENSIGNIA, Jaime (editores). Seguridad Pública en los países del Cono Sur. Los desafíos institucionales. Santiago de Chile, Fundación Friedrich Ebert. 2007. 183 p. ISBN 978956-7630-20-2.

LUNECKE, Alejandra y GUAJARDO GARCÍA, Carlos. Política de Prevención del delito en Chile: Del Programa Comuna Segura - Compromiso 100 a los Planes Comunales de Seguridad Pública. Santiago, Chile. Sin publicar. 2009. 23 p.

LUNECKE Alejandra y RUIZ, Juan Carlos. Capital social y violencia: análisis para la intervención en barrios urbanos críticos. En: DAMMERT, Lucía y ZÚÑIGA, Liza (editoras), Seguridad y violencia en América Latina. Santiago, Chile, URB-AL. 2007. ISBN: 978-956-205-219-1.

LUNECKE, Alejandra. Programa Barrio Seguro. Santiago, Chile, Programa Seguridad Urbana, Universidad Jesuita Alberto Hurtado. 2006. 12 p.
LUNECKE, Alejandra. La prevención local del delito en Chile: experiencia del programa comuna segura. En: DAMMERT, Lucía y PAULSEN, Gustavo (editores), Ciudad y seguridad en América Latina. Santiago, Chile, FLACSO. 2005. p. 151-171. ISBN: 978-956-205-204-7.

MANZANO, Liliana. Violencia en Barrios Críticos. Explicaciones teóricas y estrategias de intervención basadas en el papel de la comunidad. Santiago, Chile, Centro de Estudios en Seguridad Ciudadana, Universidad de Chile. 2009. 312 p. ISBN: 978-956-284-689-9.

MARTÍNEZ, Fernando. Sistematización de Experiencias en Terreno: Programa Barrio Seguro, Ministerio del Interior, Gobierno de Chile. Santiago, Chile, Centro de Estudios en Seguridad Ciudadana, Instituto de Asuntos Públicos de la Universidad de Chile, Documento de Apoyo Técnico No 4, Proyecto de Apoyo y Difusión de Programas, de Prevención Comunitaria del Delito. 2007. 16p.

MÁS COMUNIDAD MÁS PREVENCIÓN. Experiencia de Prevención en terreno. Programa Comuna Segura Compromiso 100. Más Comunidad más Prevención (1): 8-16. 2004.

MAZEROLLE, Lorraine, SOOLE, David y ROMBOUTS, Sacha. Street-level drug law enforcement a metaanalytical review. Journal of Experimental Criminology. (2): 409-435. 2006. ISSN 1572-8315.

revista invi № 74 / Mayo 2012 / Volumen № 27: 149-185 183 
MINISTERIO DEL INTERIOR. Programa Barrio en Paz Residencial. Santiago, Chile, Subsecretaría de Prevención del Delito, Unidad de Prevención División de Seguridad Pública. 2011.

MINISTERIO DEL INTERIOR. Modelo conceptual Programa Barrio en Paz. Santiago, Chile, Subsecretaría de Prevención del Delito, Unidad de Prevención División de Seguridad Pública. 2011. p. 15 - 19.

MINISTERIO DEL INTERIOR. Plan Chile Seguro 2010 - 2014, Santiago, Chile, Gobierno de Chile. 2010.

MINISTERIO DEL INTERIOR. Manual de Caracterización de Barrios. Barrio en Paz Residencial. Santiago, Chile, Subsecretaría de Prevención del Delito, Unidad de Prevención División de Seguridad Pública. 2010.

MINISTERIO DEL INTERIOR, FUNDACIÓN PAZ CIUDADANA, TINKER FOUNDATION INCORPORATED. Comuna Segura Compromiso Cien. Documento descriptivo Fase Uno-2001. Santiago, Chile. Ministerio del Interior. 2001. p. 59.

OLAVARRÍA GAMBI, Mauricio. Lecciones Aprendidas en los Estudios impulsados por la División de Seguridad Pública 2002 - 2009. Santiago, Chile, Sin publicar. 2010.

OTEÍZA DIAMANTE, Emiliano. Origen y destino de la delincuencia en el Gran Santiago 2009: delitos de robos con violencia o intimidación y robo en lugar habitado. EN: Actas del VI Congreso Nacional de Investigación sobre Violencia y Delincuencia. Santiago, Chile, Fundación Paz Ciudadana. 2011. p. 9-22.
RUPRAH, Inder. An impact evaluation of a Neighboourhood Crime Prevention Program: Does safer commune make chileans safer? Washington DC, Estados Unidos. Banco Interamericano de Desarrollo. 2008. p. 28.

SABATINI, Francisco; CÁCERES, Gonzalo y CERDA, Jorge. Segregación residencial en las principales ciudades chilenas: Tendencias en las últimas décadas y posibles cursos de acción. EURE. 27(82): 21-42. 2001. ISSN 0250-7161.

SAMPSON, Robert. Neighborhood and crime: the structural determinants of personal victimization. Journal of Research in Crime and Delinquency. (22):7-40. 1985. ISSN 1552-731X.

SAMPSON, R., MORENOFF, J. y GANNON-ROWLEY, T. Assessing Neighbourhood Effects: social processes and new directions in research. Annual Review of Sociology. (28): 443-478. 2002. ISSN 0360-0572.

SHAW, C. y MCKAY, H. Juvenile Delincuency and Urban Areas. Chicago, Estados Unidos, University Press, 1942.

TRUJILLO Lucía y ARÉVALO Juan Pablo. Victimización, Temor e Inseguridad en 10 Barrios Críticos de la Región Metropolitana de Santiago. EN: Congreso Internacional de Investigación sobre Violencia y Delincuencia ( $7^{\circ}, 2011$, Santiago, Chile). VII Congreso Internacional de Investigación sobre Violencia y Delincuencia. Santiago, Chile, Fundación Paz Ciudadana. 2011. 
TURRÓ ORTEGA, Claudia, RAMíREZ CORVERA, María Teresa y JACOB KRAUSE, Mariane. Una experiencia en Chile de trabajo grupal con dirigentes de organizaciones sociales. Intervención Psicosocial. 16(3): 375-392. 2007. ISSN 1132-0559.

VILLARRUBIA, Gustavo. La dictadura de los narcos que se adueñaron de La Legua. [En línea]. Ciperchile. Enero 2011. [Fecha de consulta: 15 marzo 2012]. Disponible en: http://ciperchile. cl/2011/01/10/la-dictadura-de-los-narcos-que-seaduenaron-de-la-legua/

VIVANCO, Manuel. Análisis estadístico multivariable. Teorías y prácticas. Santiago, Chile, Editorial Universitaria. 1999. p. 234, ISBN: 956-11-1458-5.

ZÚÑIGA, Liza. Conjugando estrategia nacional y política local en seguridad: el caso de Chile. Santiago, Chile, Serie Documentos Electrónicos Programa Seguridad y Ciudadanía, FLACSO Chile. 2010. 